\title{
The regulation of gut mucosal IgA B-cell responses: recent developments
}

\author{
NY Lycke ${ }^{1}$ and M Bemark ${ }^{1}$
}

The majority of activated B cells differentiate into IgA plasma cells, with the gut being the largest producer of immunoglobulin in the body. Secretory IgA antibodies have numerous critical functions of which protection against infections and the role for establishing a healthy microbiota appear most important. Expanding our knowledge of the regulation of IgA B-cell responses and how effective mucosal vaccines can be designed are of critical importance. Here we discuss recent developments in the field that shed light on the uniqueness and complexity of mucosal IgA responses and the control of protective IgA responses in the gut, specifically.

\section{INTRODUCTION}

A prime function of the mucosal immune system is the production of secretory IgA (SIgA) antibodies, which are dimers of IgA molecules joined by a J-chain and a secretory component. ${ }^{1-3}$ The IgA dimer and J-chain complex produced by the plasma cell in the lamina propria (LP) of the mucosal membrane is transported through the epithelial cell barrier after binding to the poly-Ig-receptor (pIgR) on the basolateral side of the epithelial cell. ${ }^{3,4}$ The production of SIgA is important for protection against pathogens and in regulating the composition of the commensal microbiota. ${ }^{5-8}$ Despite intense interest in mucosal vaccine development and the interactions between mucosal IgA antibodies and the microbiota, several questions remain unanswered. ${ }^{9}$ Among these questions are where and how B cells come in contact with antigen, where switching from IgM to IgA occurs, the role and function of germinal centers (GC) and CD4 T-cell subsets at mucosal sites, what are the regulatory differences between $\mathrm{T}$-dependent and -independent IgA responses, whether development of long-term memory occurs and how responses to infection or immunization differ between the small and large intestine, lung and genital tract. These questions are critical not only for mucosal vaccine development, but also for our understanding of how homeostasis can be maintained between the host and the microbiota, where an imbalance may lead to dysbiosis and severe inflammatory conditions. ${ }^{10,11}$ Therefore, recent attention has been given to the interplay between the gut microbiota and the production of IgA antibodies. There is broad consensus that development of a diverse microflora in the adult gut is associated with a healthy life. ${ }^{7}$ However, the overriding question is what is the role of gut IgA antibodies for homeostasis? Do IgA antibodies in a mother's milk help select for a healthy bacterial repertoire or are colonizing microbiota imprinting an IgA memory repertoire that, when established, maintains homeostasis? Or, perhaps, both are in operation? ${ }^{12,13}$ Alternatively, there may be genetic cues for the production of polyreactive SIgA that critically would form the repertoire of the microbiota and influence its diversity. ${ }^{14,15}$

This review reports our current understanding of how IgA B cells are activated, distributed, regulated and function in the tissues and how memory B cells and long-lived IgA plasma cells are generated and maintained. Since a review discussing the human IgA system recently was published in this journal, ${ }^{16}$ we will focus exclusively on knowledge gained from experimental work in the mouse model.

\section{ORGANIZATION OF IGA B-CELL INDUCTIVE SITES IN THE GUT INTESTINE}

The majority of mucosal IgA plasma cells are derived from B-cell activation in mucosal associated lymphoid tissues (MALT). These are organized lymphoid tissues strategically located in close proximity to mucosal surfaces, which lack afferent lymphatics and are covered by a specialized follicle 
associated epithelium (FAE) ${ }^{17}$ The majority of MALT is localized along the gut and, hence, termed gut-associated lymphoid tissues (GALT). These are functionally strongly influenced by the gut microbiota. ${ }^{10}$ Because most of our current understanding of the IgA B-cell response emanates from GALT, we will use gut intestinal IgA responses to describe the general features of MALT. However, of particular note is that the microbiota will dramatically affect not only gut IgA production, but also strongly influences lung IgA production via lung $\mathrm{CD}_{103}{ }^{+}$dendritic cells (DC) as well as IgA production in the mammary glands. ${ }^{12,18,19}$

The FAE hosts specialized "microfold" $(\mathrm{M})$ cells that transport luminal antigens into the underlying lymphoid follicle through transcytosis. ${ }^{20}$ Epithelial stem cells undergo differentiation to $\mathrm{M}$ cells, after stimulation via the receptor activator of nuclear factor- $\kappa \mathrm{B}$ ligand (RANKL) on mesenchymal cells, which induces expression of the transcription factor Spi-B. ${ }^{21-24}$ Mice that lack RANK in the intestinal epithelium or RANKL on mesenchymal cells produce reduced levels of SIgA in the gut and IgA coating of commensal bacteria develops slowly, demonstrating the importance of functional $\mathrm{M}$ cells for antigen uptake and gut SIgA responses. ${ }^{24,25}$ In addition, an alternative pathway for antigen to cross the mucosa was recently described that use retrograde transport through goblet cells. ${ }^{26}$ However, such retrograde transport appears not to compensate for a lack of $\mathrm{M}$-cell function, but rather is responsible for inducing tolerance in mesenteric lymph nodes (MLN), which also involves migrating $\mathrm{CD}_{103}{ }^{+}$DC from the LP. ${ }^{27,28}$ In fact, this latter pathway was initially described for $\mathrm{CD}_{103}{ }^{+} \mathrm{DC}$ that collaborate in the intestinal LP with CX3CR1 ${ }^{+}$macrophages, which send out transepithelial dendrites to sample luminal antigen. ${ }^{29-31}$

The GALT comprises several structures of which the Peyer's patches (PP) are the most important IgA-inductive sites (Figure 1). ${ }^{32}$ These are macroscopically visible clusters of follicles in the small intestine. Much less visible clusters exist in the large intestine, termed colonic patches $(\mathrm{cP})$, but the precise function of $\mathrm{cP}$ still remains to be investigated. ${ }^{33-35}$ Moreover, hundreds of single follicles are present along the entire mouse small intestine, referred to as isolated lymphoid follicles (ILF), but these appear to function more as a safety resource when the PPs are failing (Figure 2). ${ }^{36-38}$ Thus, at homeostasis few ILFs host GC and it is only with bacterial overgrowth that ILF develop significant GC reactions. ${ }^{36,39,40}$ Also, the cecum may play a specific role for IgA production in the colon, but the precise function needs to be analyzed in more detail. ${ }^{41}$
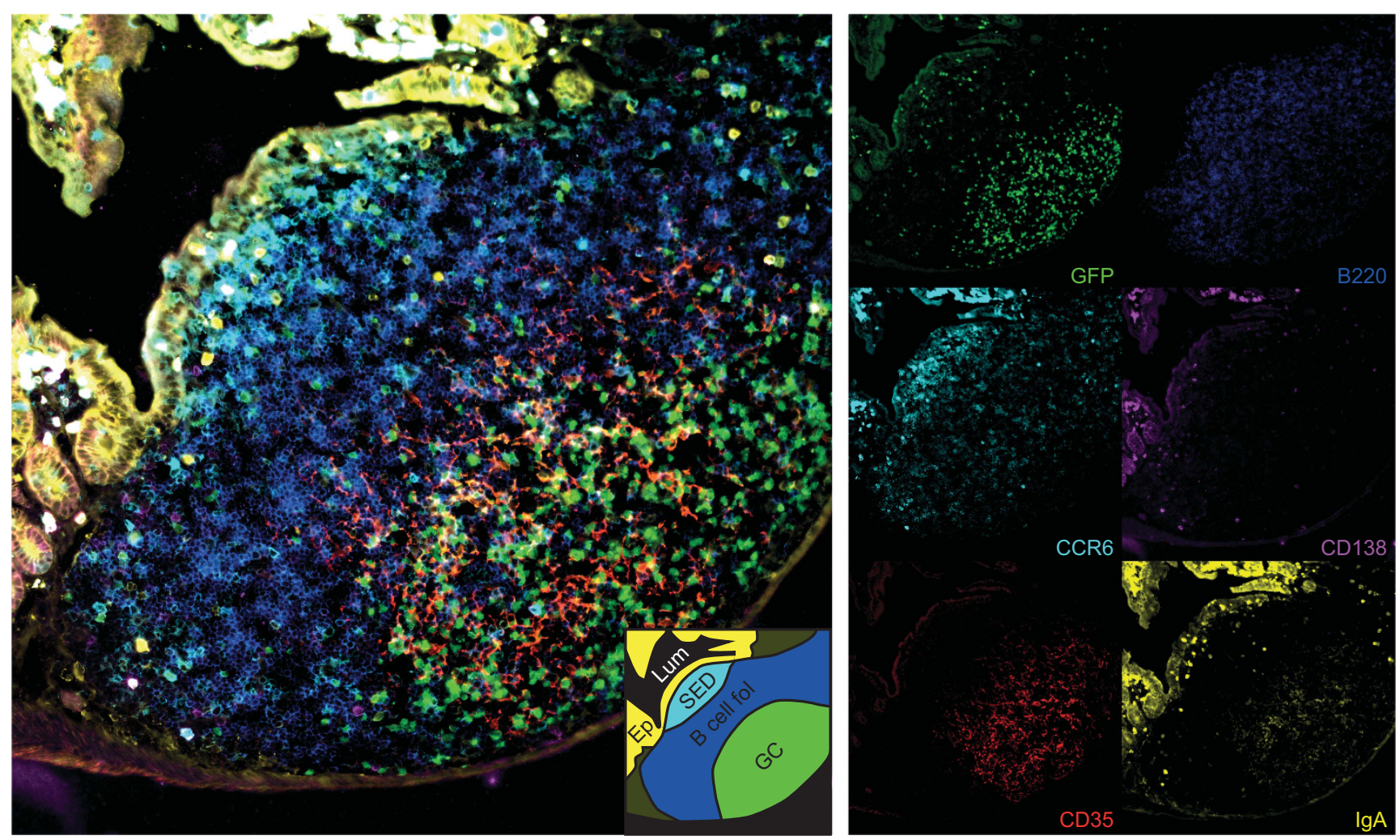

Figure 1 The localization of B cells in PP after oral immunization with NP-CT. To the left is shown the localization of GFP-expressing NP-specific $B$ cells in PP 1 week after immunization. The insert shows the position of the germinal center (GC), the B-cell follicle (B-cell fol), the subepithelial dome (SED), the epithelium (Ep) and the gut lumen (Lum). Antigen-specific GFP-expressing B cells are located in the GC and the SED. Noteworthy, IgA overlaps with CD35 (labeling the FDC network) in the follicle, suggesting that IgA is associated with FDCs and likely part of immune complexes. The individual channels are shown to the right marked with the respective antibody used for staining. The PP was visualized using an Axioplan Carl Zeiss microscope set up for filter-dense multicolor microscopy. ${ }^{194}$ Individual images for each filter were imported into ImageJ for preparation of composite images. 

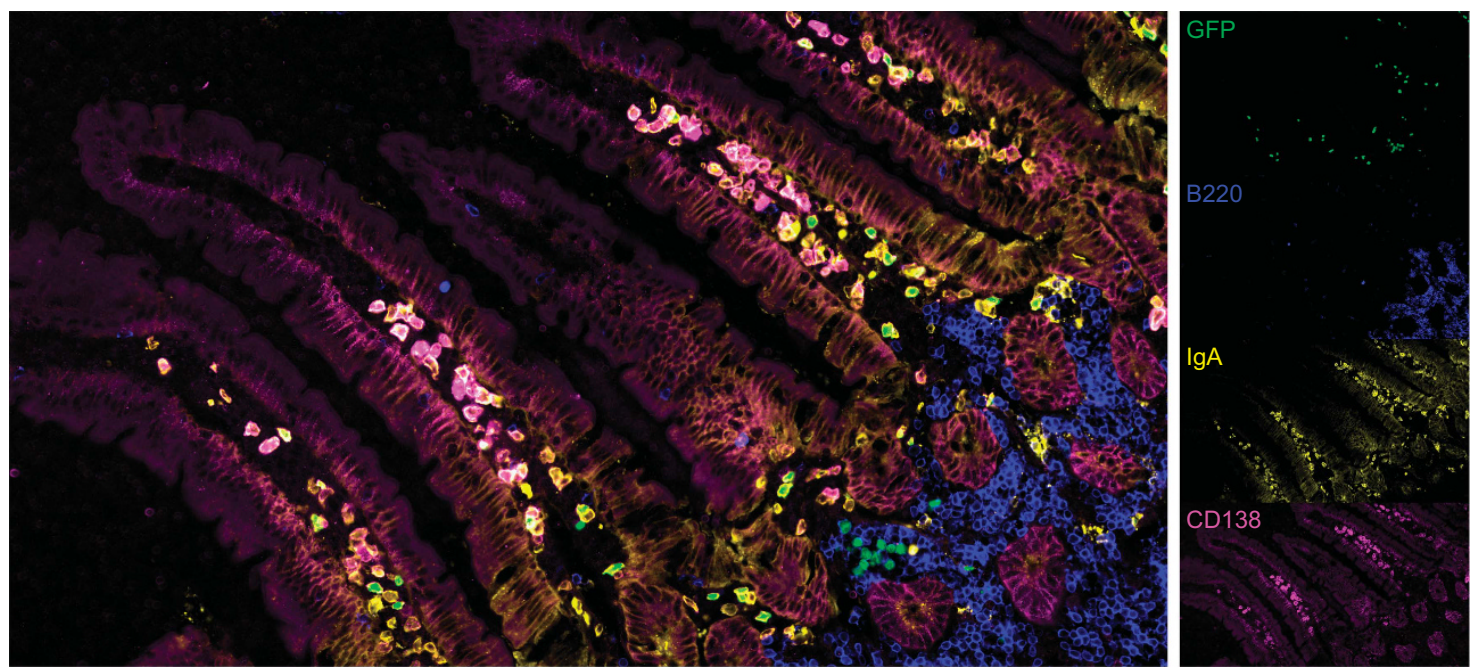

Figure 2 NP-specific IgA producing plasma cells in the lamina propria following oral NP-CT immunization. A frozen gut-intestinal section from mice orally immunized with NP-CT and labeled with antibodies against B220, IgA and CD138 (left panel), with individual channels shown in the right panels. NP-specific GFP-expressing plasma cells are present among the $\lg \mathrm{A}^{+}$and $\mathrm{CD}_{138^{+}}$plasma cells in the lamina propria of the small intestine. Below the lamina propria is an isolated lymphoid follicle (ILF) that harbors $\mathrm{B}_{220}{ }^{+} \mathrm{B}$ cells. Note the scarcity of B220-staining outside of organized lymphoid tissues. The staining of the sections was performed as in Figure 1.

In addition, certain bacteria can induce the formation of de novo tertiary lymphoid structures in cases of gut inflammation. ${ }^{42,43}$ Even though the MLN are not strictly GALT and are not in direct contact with the gut lumen, they receive afferent lymphatics from the gut and activated lymphocytes that migrate from PP. ${ }^{17}$ Whether specific IgA B-cell responses can initiate from MLN is still debated ${ }^{38,44,45}$ but MLN have a critical role for maintaining gut homeostasis as tolerance induction in gut $\mathrm{T}$ cells occurs at this site. ${ }^{46}$ Noteworthy, the spatially separated follicles of MLN drain lymph from distinct parts of the intestine, i.e. small and large intestine, and appear to differ in which antigens they are exposed to, their ability to metabolize vitamin $\mathrm{A}$ and promote expression of the gut homing receptors, CCR9 and $\alpha_{4} \beta_{7}$, in activated lymphocytes, as will be discussed later. ${ }^{47}$

Following activation, expansion and maturation of specific $B$ cells in PP the plasma cell precursors migrate through the lymph via the thoracic duct into the blood after which they can home back to the LP in the intestinal villi. ${ }^{48}$ This way the IgA plasma cells seed the LP in the small and large intestine. The homing process is controlled by expression of specific homing receptors, where PP induced plasmablasts express $\alpha_{4} \beta_{7}$, CCR9, and CCR10, restricting their migration to the small and large intestine. ${ }^{4-52}$

\section{ANTIGEN UPTAKE AND INDUCTION OF IGA B-CELL RESPONSES}

Dendritic cells, $\mathrm{T}$ and $\mathrm{B}$ cells in the subepithelial dome region (SED) of GALT, immediately beneath the FAE, are exposed to antigens taken up via the $\mathrm{M}$ cell. ${ }^{20}$ Antigen presented by DC in SED can activate $\mathrm{T}$ and $\mathrm{B}$ cells in situ, but DCs can also migrate to intrafollicular T-cell areas in PPs where they prime CD4 T cells that together with the activated B cells form GC in the B-cell follicle. ${ }^{53,54}$ Direct interactions between DC and B cells in
SED may play an important role in the generation of $\operatorname{Ig} \mathrm{A}$ responses as activated B cells upregulate CCR6, which allows them to migrate to SED where the ligand, CCL20, is being produced. ${ }^{55}$ This way $\mathrm{B}$ cells in $\mathrm{PP}$ may also function to transport antigen from the SED to the GC (see below) and initiate IgA class switch recombination (CSR) at a pre-GC stage. ${ }^{55}$ The latter is because DCs located to the SED express $\alpha v \beta 8$ integrin, which activates latent TGF- $\beta$. Moreover, DCs outside of the GALT can play an important role for SIgA production as both ILF and LP contain large numbers of DC, and among these especially cells that produce both nitric oxide and tumor-necrosis factor (TNF), so called Tip (TNF and iNOS producing) DCs, as well as TLR5 ${ }^{+}$and plasmacytoid DC have been found to support IgA B-cell differentiation. ${ }^{56-58}$ Although earlier studies in both mice and humans indicated that LP could be a site for IgA CSR, more recent investigations have shown little support for IgA CSR in the unorganized gut LP in mice $^{35,42,59-62}$ The potential for any significant IgA CSR in the LP is poor because of the lack of B-cell proliferation, which is a prerequisite for IgA CSR. ${ }^{59,63-65}$ In addition, when B cells have completed IgA CSR they express short-lived circular $\alpha$ transcripts $(\mathrm{CT} \alpha)$ from IgA switch circles, which has not been well documented in LP. ${ }^{35,59,60,66}$ Also, only low levels of mRNA for the AID enzyme, responsible for IgA CSR, has been detected in LP, which, in fact, could have occurred at other sites than the LP. ${ }^{35,60,67}$ By contrast, DCs, B and T cells in ILF or tertiary lymphoid tissues make close contact, promoting an IgA-inductive function in this tissue, and, indeed, this has been observed in the absence of PPs or when overgrowth of the microbiota has occured. ${ }^{42,43,68}$

\section{THE GERMINAL CENTER REACTION AND IGA CSR}

As aforementioned, the dominant inductive site for IgA B-cell responses in GALT is the PP (Figure 1). ${ }^{35,54}$ These organized 
lymphoid tissues differ in several aspects from other inductive sites in peripheral lymph nodes or spleen. ${ }^{32,69,70}$ However, similar to other secondary lymphoid tissues the formation of GC in PP plays a critical role for the development of affinitymatured IgA B cells and the formation of long-lived plasma and memory $\mathrm{B}$ cells. ${ }^{71-73}$ Following antigen-activation in nonmucusal tissues, B-cell expansion occurs and GC are formed in the B-cell follicles. This formation requires the concomitant expansion and differentiation of follicular helper $\mathrm{T}$ cells $\left.\left(\mathrm{T}_{\mathrm{FH}}\right)\right)^{74,75}$ In the dark zone of the GC, large numbers of random mutations are introduced into the immunoglobulin (Ig) heavy and light chain genes during rapid proliferation, resulting in random clonal variants that move into the light zone of the GC. ${ }^{76,77}$ At this site higher affinity B cells are selected through interactions with antigens presented as immune complexes on the follicular dendritic cells (FDC), which form a network in the GC. ${ }^{78} \mathrm{CD} 40$ and $\mathrm{CD} 40 \mathrm{~L}$ interactions between $B$ and $T_{F H}$ cells are critical for $G C$ formation, and blocking this interaction effectively disrupts the GC also in the PP. ${ }^{71,79}$ Contrary to other inductive sites, the PP consistently exhibit GC due to the presence of the microbiota and of food antigens in the lumen, a process which may not always require antigen-specific recognition. ${ }^{48,80}$

Whether the GC is required for IgA CSR has been investigated in detail and two studies have documented that this can occur at a pre-GC stage. ${ }^{35,55}$ We reported in CD40-deficient mice that despite no GC in the PP, their gut LP hosted near normal IgA plasma cell levels. ${ }^{35,59}$ The absence of GC was, nevertheless, accompanied by detection of the markers of IgA CSR in PP, i.e., AID expression and germline Ig alpha gene (GL $\alpha$ ) and shortlived IgA post-switch circle transcripts (CT $\alpha$ ), the best evidence of recent IgA CSR. ${ }^{59,61,66,81}$ In fact, we identified that $G L 7^{\text {int }} \mathrm{B}$ cells in the PP from both CD40-deficient and WT mice expressed AID as well as post-switch $\mathrm{CT} \alpha$, but had not undergone significant SHM. ${ }^{35}$ Hence, the most active stage of IgA CSR could be prior to a manifest GC stage and could be identical to a stage of B-cell differentiation previously reported in AID expressing B cells in PP of TCR $\beta / \delta$-deficient mice. ${ }^{82}$ Consistent with the concept of extensive pre-GC CSR is the observation that the majority of $\operatorname{IgA}^{+} \mathrm{B}$ cells in PP express AID and CD95. ${ }^{67}$ This notion also agrees with observations made by Cyster and coworkers, who recently reported that IgA CSR may occur in the SED at a CCR6 ${ }^{+}$stage prior to entering the $\mathrm{GC}^{55}$

In IgA CSR, DNA is deleted from the antibody heavy chain constant $(\mathrm{C})$ region to allow juxtaposition of the IgA C region to the antigen-binding variable $(\mathrm{V})$ region, which carries the gene sequences responsible for affinity selection. ${ }^{38,81,83}$ The enzyme AID is strictly required for both SHM and CSR and high levels of AID is found in activated B cells in the GALT. ${ }^{84,85}$ To be functional AID requires cell division and, hence, absence of cell division, as observed in B cells in the LP, argues against IgA CSR at this location. ${ }^{59,63-65}$ In CD40-deficient mice, SIgA antibodies are directed against T-cell-independent antigens, most likely derived from the microbiota. ${ }^{59}$ These SIgA antibodies represented largely unmutated IgA plasma cells in the LP, whereas, by contrast, essentially all IgA plasma cells in wild-type (WT) mice have been found to carry multiple mutations, suggesting that SHM may also occur in T-cellindependent IgA B-cell responses in WT mice. ${ }^{35,86}$ Therefore, we launched a theory, which proposes that activated B cells, even when activated by $\mathrm{T}$-cell-independent antigen, undergo clonal diversification in already established GC in GALT, despite that cognate interactions with $\mathrm{T}_{\mathrm{FH}}$ cells appear unlikely. ${ }^{72}$ This theory is supported by studies by Pabst and co-workers who have found extensive mutations in the vast majority of IgA-genes from isolated LP cells of wild-type mice using next-generation sequencing. ${ }^{12,86,87}$ Indeed, IgA B cells reactive to LPS, a T-cell-independent antigen, were mutated in humans. ${ }^{87}$

\section{IGA CLASS-SWITCH FACTORS AND OTHER IGA PROMOTING FACTORS}

Following B-cell receptor (BCR) signaling, IgA CSR proceeds along a defined pathway of differentiation where multiple signals influence the process. ${ }^{88,89}$ However, TGF- $\beta$ is the critical switch factor that controls IgA CSR. ${ }^{90}$ Specific lack of TGF- $\beta$ receptors on $B$ cells result in a dramatically reduced IgA CSR, only few IgA plasma cells in the gut LP and failure to respond to oral immunizations. ${ }^{91,92}$ The mechanism of action for TGF- $\beta$ is via binding of SMAD3/4 and Runx 3 to a TGF- $\beta$ responsive element in the I $\alpha$ promoter of the IgA heavy chain gene, which activates GL $\alpha$ transcription. ${ }^{90}$ The regulation of TGF- $\beta$-activity is complex because it is produced in a latent form and only after exposure to proteases, certain integrins, thrombospondin 1 or physical stress in the extracellular matrix does it become active. ${ }^{93}$

There are several other factors that affect IgA production and possibly directly influences IgA CSR. Some of these elements are endogenous to the $\mathrm{B}$ cell, while both $\mathrm{DC}$ and $\mathrm{CD} 4 \mathrm{~T}$ cells critically influence IgA CSR and IgA production in PP ${ }^{94,95}$ For example, CD40-CD40L-signaling and multiple cytokines induce transcription from the $\mathrm{I} \alpha$ promoter. ${ }^{38,81,96}$ In fact, for IgA CSR, CD40- and TLR signals are important, but neither is essential for IgA CSR to take place. ${ }^{56,59,97}$ Furthermore, a proliferation-inducing ligand (APRIL) or B-cell activating factor (BAFF), belonging to the TNF family binding to the transmembrane activator and calcium modulator and cyclophilin ligand interactor (TACI), promote IgA production partly by inducing GL $\alpha$ transcripts. ${ }^{96}$ Indeed, TACI or APRILdeficient mice have low levels of serum IgA but normal levels of IgG, suggesting specific roles for $\operatorname{IgA}$ production. ${ }^{98-101}$ However, APRIL and BAFF are also important B-cell survival factors, and may primarily support IgA B-cell survival rather than IgA CSR. ${ }^{102}$ In addition, nitrogen oxide produced by iNOS-expressing cells can promote IgA differentiation, possibly via regulation of TGF- $\beta$ receptor II expression on B cells and thereby GL $\alpha$ transcription, and iNOS-deficient mice exhibited decreased levels of SIgA. ${ }^{56}$ More importantly, mucosal DC produce the enzyme retinaldehyde dehydrogenase $(\mathrm{RALDH})$ that generates all-trans-retinoic acid (RA) from vitamin A. Binding of RA to its nuclear receptor induces expression of $\alpha_{4} \beta_{7}$ integrin and CCR9 on activated B and T lymphocytes, securing gut homing properties. ${ }^{94}$ But, RA has 
multiple functions apart from imprinting homing receptors. Among them is IgA production, which specifically can be augmented through a RA response-element in the I $\alpha$ promotor, thereby enhancing TGF- $\beta$-induced transcription. ${ }^{103,104}$ Hence, RA influences IgA CSR and depletion of vitamin A (RA precursor) strongly impairs IgA production. ${ }^{105}$ In addition to these factors, IL-21 appears to be critical for IgA CSR. ${ }^{106} \mathrm{~T}_{\mathrm{H}} 17$ and follicular helper $\mathrm{T}$ cells $\left(\mathrm{T}_{\mathrm{FH}}\right)$ express high levels of IL-21. This greatly influences IgA production in the intestine, while serum IgA production is less affected. IL-21 induces Aicda mRNA expression and, in particular together with TGF$\beta$-stimulation, greatly enhances IgA CSR and the acquisition of gut homing markers on the differentiating $B$ cells. ${ }^{106}$ Both IL-21 or IL-21R deficient mice produced significantly lower levels of IgA in the gut and lung. ${ }^{106,107} \mathrm{~T}_{\mathrm{H}} 17$ cells also produce IL-17 and lack of IL-17 influences overall gut secretion of IgA, but, IL-17 signals do not seem to directly influence IgA CSR in B cells. ${ }^{106,108,109}$ Rather, a combination of TGF- $\beta$, RA and IL-21 strongly promoted IgA production from activated B cells, possibly also involving an inhibitory effect of IL- 21 on TGF- $\beta$ driven GL $\gamma 2 \mathrm{~b}$ gene transcription, and, in this way, IgA CSR and production was augmented. ${ }^{106,110}$

\section{THE ROLE OF FOLLICULAR DENDRITIC CELLS FOR IGA B-CELL RESPONSES}

Non-hematopoietic cells play critical roles in B-cell expansion and differentiation. This is also true for GALT and the PP, in particular. Most prominently, follicular dendritic cells (FDC) are important for the formation of GC, and in this way influence IgA B-cell development. ${ }^{111}$ Because FDC are known to present antigen complexes to B cells in the light zone, they critically control the selection of high-affinity B cells during the response. ${ }^{78}$ Given the efficiency of selection and affinity maturation in $\mathrm{PP},{ }^{112}$ the FDCs in PP most likely present tethered antigens as documented in peripheral lymph nodes and spleen. Interestingly, IgA deposition in PP GC follows the distribution of the FDC network, which resembles that of immune complexes (IC) in other secondary lymphoid tissues (Figure 1) ${ }^{113}$ Contrary to IgG and IgM, though, IgA does not activate complement, which argues against involvement of complement receptors for trapping IgA-IC on the FDC. ${ }^{114}$ Moreover, despite the presence of $\mathrm{Fc} \alpha / \mu \mathrm{R}$ on FDC in PP, it appears that this receptor would rather inhibit than promote GC formation and IgA responses. ${ }^{115}$ Therefore, one possibility for a role of IgA in affinity maturation, could be that high-affinity IgA antibodies substituted low affinity IgM or IgG on already captured IC, as has been previously suggested. ${ }^{116}$ This way GC-derived IgA plasma cells would restrict low affinity antigen access and thereby, establish a selection pressure, accelerating the emergence of $B$ cells of the highest affinities, only.

Continuous and combined stimulation of FDC through TLR and RA receptors can induce chemokines, survival factors, and molecules involved in the Myd88-pathway dependent expression of BAFF and TGF- $\beta 1$, which all can contribute to enhancing IgA B-cell differentiation. ${ }^{111}$ Also, antimicrobial peptides produced in the gut, such as cathelin-related antimicrobial peptide (CRAMP; the mouse counterpart to LL-37) may have similar functions. ${ }^{117}$ Hence, it is feasible that PP FDCs are conditioned by environmental cues to express surface receptors required to sustain IgA-IC in PP to facilitate high-affinity B-cell selection as well as express factors that regulate IgA responses. Interestingly, follicular dendritic cell secreted protein (FDC-SP) is a suppressive factor on IgA B-cell responses and FDC-SP-deficient mice have enhanced IgA production in PP. ${ }^{118}$ Apart from FDCs other stromal cells can produce IgA promoting chemokines and express LT $\beta R$ and, indeed, epithelial cells can secrete BAFF and APRIL, which dramatically affect IgA differentiation. ${ }^{68}$ The roles of these cell types have been difficult to study in gene deficient animals, but one study showed that over-expression of TLR4 in epithelial cells lead to increased numbers of IgA plasma cells through production of APRIL. ${ }^{119}$ Furthermore, mesenchymal stromal cell membrane expression of RANKL in the SED is critical for M-cell differentiation and CCL20-dependent interactions between DC and B cells. ${ }^{24}$ Consequently, a mesenchymal cell-specific deletion of RANKL resulted in a reduction of specific IgA responses and loss of microbial diversity.

\section{$T_{F H}$ AND OTHER CD4 T-CELL SUBSETS IN THE REGULATION OF IGA B-CELL RESPONSES}

The composition of different functional CD4 T-cell subsets in the PP is complex and distinct from that in systemic organs. Exactly what unique contributions these subsets have on the different stages of IgA B-cell differentiation awaits to be further investigated. ${ }^{120-122}$ Recently identified CD4 T-cell subsets includes the $\mathrm{T}$ follicular helper $\left(\mathrm{T}_{\mathrm{FH}}\right)$ and regulator $\left(\mathrm{T}_{\mathrm{FR}}\right)$ populations. ${ }^{123}$ The $\mathrm{T}_{\mathrm{FH}}$ interact with the activated $\mathrm{B}$ cells in a cognate fashion, meaning that TCR-MHC class II/peptide recognition is required. ${ }^{124}$ However, there also exist other interactions of which CD40-CD40L is critical for GC formation and for expanding and differentiating the B-cell response. ${ }^{125,126}$ Other CD4 T-cell subsets found in PP are $\mathrm{T}_{\mathrm{FR}}$ and Foxp3 ${ }^{+}$ Tregs. ${ }^{127,128}$ The former appears to be derived from natural Tregs, but can also be generated from antigen-specific and naïve CD4 T cells. ${ }^{129,130} \mathrm{~T}_{\mathrm{FR}}$ cells undergo similar phenotypic differentiation as the $\mathrm{T}_{\mathrm{FH}}$ subset in systemic organs, i.e., express PD-1 and CXCR5, and suppress B-cell responses/ $\mathrm{T}_{\mathrm{FH}}$ function through a mechanism dependent on IL-21. ${ }^{131}$ Whether this is also the case in PP GC is poorly studied. ${ }^{127} \mathrm{PD}-1$-deficient mice have enhanced $\mathrm{T}_{\mathrm{FH}}$ levels in GC but reduced ability to produce IL-21, and this appears to reduce the ability to produce affinitymatured gut IgA antibodies, leading to dysbiosis and defects in the mucosal barrier. ${ }^{132}$ The origin of $\mathrm{T}_{\mathrm{FH}}$ cells in the GALT has been debated and two models exist where they either are derived from Foxp $3^{+}$Tregs or are generated from Th17 cells. ${ }^{95,133}$ However, there is large plasticity among $\mathrm{CD} 4{ }^{+}$cell populations in the gut, and it is conceivable that Th1 or Th2 polarized cells may also contribute to the $\mathrm{PP}_{\mathrm{FH}}$ population. ${ }^{134}$ Interestingly, when Tregs and Th17 cells are converted to $\mathrm{T}_{\mathrm{FH}}$ they down-modulate their original phenotypes and support gut IgA production. ${ }^{95,133}$ Whereas it was reported that Ror $\gamma \mathrm{t}$ expressing $\mathrm{CD} 4 \mathrm{~T}$ cells are critical for gut IgA production and 
for mucosal IgA responses to oral immunization with cholera toxin (CT), to what extent the Th17 subset is directly responsible for IgA CSR and B-cell differentiation in PP awaits to be further investigated. ${ }^{108,109,133}$ While Th17 cells could contribute cytokines such as IL-17 and IL-21 when becoming PP $\mathrm{T}_{\mathrm{FH}}$ cells, Foxp ${ }^{+} \mathrm{CD} 4{ }^{+} \mathrm{T}$ cells do not appear to support IgA switching through cannonical TGF- $\beta$ production but rather through IL-21 and by ensuring a balanced development of $\mathrm{T}_{\mathrm{FH}}$ and $\mathrm{T}_{\mathrm{FR}}$ cells in PP. ${ }^{106,109,128}$ However, mucosal Tregs have been reported to promote IgA B-cell responses in other ways. ${ }^{135,136}$ In fact Tregs, located close to the B-cell follicle, can deprive the GC of IL-2, a cytokine known to prevent Bcl-6 expression in $\mathrm{T}_{\mathrm{FH}}$ precursor cells. ${ }^{137-140}$ Hence, Tregs could in this way promote IgA production. Finally, it appears that prolonged antigen exposure stimulates the accumulation of resident memory CD4 T cells in PP. ${ }^{141}$ These resident memory CD4 T cells may be instrumental in the ability to rapidly replenish the plasma cell repertoire and for the strong memory IgA B-cell responses elicited after re-exposure to oral antigen, as will be discussed later. ${ }^{71,86}$

Similar to the bone marrow, survival niches exist in the gut LP that support the presence of IgA plasma cells for many months, although most gut plasma cells likely have a shorter turnover. ${ }^{45,71,142}$ The longevity of plasma cells may be regulated by gut Treg cells as anti-CD25 Mab depletion rendered mice deficient in intestinal IgA. ${ }^{135}$ Also Th17 cells could be critical for maintaining IgA plasma cells in the gut LP, not only because IL-17 is involved in pIgR-mediated transepithelial transport of SIgA, but because they could provide a microenvironment that is supportive of plasma cell survival. ${ }^{108}$ Hence, both Th17 and Tregs may coordinately influence IgA plasma cell survival niches. Besides the T cells, epithelial cells, eosinophils and DCs in the gut mucosa can make CXC-chemokine ligand 12 (CXCL12), IL-1 $\beta$, IL-6, BAFF, and APRIL, factors that are known to support plasma cell survival niches. ${ }^{45,143,144}$ Indeed, eosinophils may be particularly important for this survival niche in the bone marrow as well as in the gut. ${ }^{145}$

\section{IGA PRODUCTION AND THE GUT MICROBIOTA}

The composition of the microbiota shape the IgA production, and, conversely, the IgA produced influences the composition of the microbiota. ${ }^{7}$ This complex interrelationship appears critically important for a healthy life as dysfunctions in this balance may lead to dysbiosis and inflammation in the gut. ${ }^{10,146}$ Accordingly, in germ-free mice, little IgA is produced, but the levels rapidly increase upon bacterial colonization. ${ }^{147}$ In addition, mono-colonization of germ-free mice has demonstrated that bacterial species differ in the levels of $\operatorname{IgA}$ they induce. ${ }^{42}$ Some of these differences are due to changes in the expression of $\mathrm{pIgR}$ and factors affecting dimeric IgA transport, but also increased formation of IgA plasma cells in the PP could be involved. ${ }^{42}$ Among the most effective are segmented filamentous bacteria (SFB). ${ }^{148}$ These bacteria induce maturation of ILF, activation of GC in PP and even formation of tertiary lymphoid tissues in the gut. They also promote the development of Th17 and other lineage T cells. ${ }^{42,149,150}$ Studies of SFB have been difficult, since it was previously not possible to cultivate them, but recent progress now allows for in vitro growth. ${ }^{151}$ Another interesting type of non-cultivable bacteria, Alcaligenes, were shown to drive IgA production after invading PP and ILF. ${ }^{152}$ However, even short-term reversible colonization with Escherichia coli K-12, a strain that is relatively poor at inducing antibody responses, leads to long-term production of $\operatorname{IgA}$, indicating that neither specific bacterial strains nor continuous stimulation are absolute requirements for IgA production. ${ }^{153}$ In fact, even infection of germ-free mice with murine norovirus induced significant production of IgA in the small intestine and colon. ${ }^{154}$ Microbial stimuli differ in the level of antigen-specificity they induce, with some triggering primarily a specific and others a more broadly reactive IgA response. ${ }^{42}$ Interestingly, even microbial production of shortchain fatty acids from dietary fiber can stimulate broadly reactive SIgA antibodies in the gut. ${ }^{155}$

IgA antibodies reactive to commensal bacteria are found in gut secretions, but not in serum, and it was, therefore, proposed that some SIgA antibodies are involved in controlling the systemic spread of commensal bacteria. ${ }^{156}$ Indeed, B-celldeficient mice are less effective in controlling bacterial translocation and spread to MLN. ${ }^{157}$ Nevertheless, gut SIgA profoundly influences the composition of the microbiota, and a remarkably large proportion of gut bacteria in the small intestine are coated with $\operatorname{IgA} .{ }^{158}$ Although IgA coating was initially proposed to be a mechanism for uptake of invasive bacteria, this would also allow for non-invasive commensal bacteria to enter PP. ${ }^{25,159}$ In fact, when IgA production was reintroduced into $\mathrm{AID}$-deficient mice, imbalances in the composition of the intestinal microbiota were reversed. ${ }^{160}$ In addition, using a model with a mutated AID enzyme that supported IgA CSR but not SHM, it was demonstrated that the effect was ascribable to the absence of affinity-matured specific SIgA antibodies. ${ }^{161}$ Moreover, PD-1-deficient mice exhibited a dysbiotic microbiota, due to poor selection of affinity-matured SIgA antibodies as a consequence of the increased frequency of $\mathrm{T}_{\mathrm{FH}}$ cells in PP GC. ${ }^{132}$ Furthermore, in a model where FoxP3expressing $\mathrm{T}$ cells were studied, reciprocal interactions between the microbiota and IgA in the gut shaped both the bacterial compartment and the production of $\operatorname{IgA}{ }^{128}$ Also, pIgR deficient mice, that cannot transport dimeric $\operatorname{IgA}$ into their milk, exhibited a less diverse microbiota, emphasizing that SIgA antibodies may greatly influence the composition of the gut microbiota, even long after weaning. ${ }^{162}$

SIgA do not only affect the bacterial repertoire of the gut microbiota, but could also influence the level of inflammation in the intestine. For example, specific SIgA appears to prevent spread of pathogens due to cross-linking of dividing bacterial cells, termed enchaining bacterial growth, and in this way facilitate pathogen clearance. ${ }^{8}$ Furthermore, mono-colonization with Bacteroides thetaiotaomicron demonstrated that specific IgA antibodies against a single bacterial capsular polysaccharide impaired activation of innate immunity without reducing bacterial density, placing emphasis on the antiinflammatory effect of SIgA. ${ }^{163}$ In addition, pups breast-fed by 
an IgA-deficient mother exhibited greatly enhanced $\operatorname{IgA}$ responses against the microbiota, while pups to an IgAproficient mother developed lower IgA responses while breast feeding. ${ }^{164,165}$ By contrast, bacterial strains densely coated with SIgA caused colitis when transferred into germ-free mice, and SIgA-coated bacteria from IBD patients were found to be colitogenic. ${ }^{159}$ Bacterial strains present in the small intestine were more often coated with SIgA than those restricted to the colon, but whether these antibodies were generated from TD or TI antigens was not completely delineated. ${ }^{158}$ However, overall the results suggested that TD and TI responses, identified nonoverlapping commensal bacterial taxa with most $\operatorname{IgA}^{+}$bacteria emanating from TI responses, while atypical commensals, such as $\mathrm{IgA}^{+}$SFBs, exclusively represented TD responses. Also, gnotobiotic mouse studies of fecal samples collected from undernutritioned Malawian children have identified diseasepromoting/dysbiotic IgA-coated bacterial species (among them Enterobacteriacae) that transmit weight loss and disrupted barrier functions, but which could be counteracted by two other IgA-coated bacterial species with an ameliorating effect isolated from nutritionally healthy individuals. ${ }^{166}$ Therefore, presently it appears that SIgA antibodies bound to bacteria in the gut could be generated as TI or TD responses and be of different qualities, highly specific, broadly cross-reactive or even promiscuously polyreactive SIgA antibodies. This confusing picture may partly be explained by recent findings from Rescigno and collegues. ${ }^{14,15}$ These authors reported on a genetic difference between $\mathrm{C} 57 \mathrm{BL} / 6$ and $\mathrm{Balb} / \mathrm{c}$ mice in the diversity of their IgA repertoire, which correlated to the diversity of their respective microbiota. In fact, polyreactive IgA antibodies in the gut of Balb/c mice allowed for a better uptake of bound bacteria in the PP, which triggered the production of specific IgA antibodies and promoted a greater diversity in subsequent bacterial colonization of the intestine. Genetic factors controlling a diverse polyreactive IgA production may, thus, critically influence the chances of establishing a diverse microbiota based on the production of specific IgA antibodies against these non-invasive bacteria. Therefore, the genetic drivers of IgA production may be more critical for homeostasis than exposing the gut to an elaborate microbial flora, which could be decisive for whether probiotic treatments will work or not. $^{167}$

\section{SYNCHRONIZING GUT IGA RESPONSES}

During systemic immune responses, de novo GC formation occurs in B-cell follicles of spleen and lymph nodes as a consequence of B-cell activation and proliferation. The GC reaction is well established 7 days after immunization, usually peaks a week later and then gradually declines with kinetics, at least partly, dependent on how quickly the antigen is cleared from the tissue. ${ }^{168,169}$ By contrast, the conditions in GALT and the PP, in particular, are completely different, where GCs are constantly present due to food antigens and the microbiota. ${ }^{72}$ Hence, these GC could function to support the response to multiple antigens and allow activated $\mathrm{B}$ cells to exploit preexisting GC in PP. In fact, this possibility was supported by our observation that the same B-cell clones appeared in multiple GC in different PPs in the same mouse. ${ }^{112}$ We found that antigen-specific B-cell clones were closely related not only in multiple PPs, but also in MLN, suggesting that early after activation $\mathrm{B}$ cells migrated to different PPs and MLN, where they continued to participate in affinity selection and differentiation. This way, the IgA plasma cell response in the gut LP could be synchronized to represent the high-affinity clones that were selected at different sites. Indeed, when we analyzed the clonality of the IgA response in the gut LP to a specific epitope, the NP hapten, we found that it was strictly oligoclonal and was dominated by cells that carried the highaffinity mutation $V_{H} 186.2 \mathrm{~W} 33$ to L33 in the CDR1 region. ${ }^{112}$ When analyzing NP-specific IgA sequences that used the $V_{H} 186.2 \mathrm{~V}$ region, it was observed that clonally related B cells representing 3-6 clones were found in multiple PPs in the same mouse, suggesting that the expansion of these clones was synchronized and the consequence of an antigen-driven selection process. Thus, after activation NP-specific B cells leave the GC and migrate to re-utilize already established GC in multiple other PPs (Figure 3). The phenomenon of re-utilization of existing GC in lymph nodes has been described previously by Or-Guil and co-workers, who discussed possible recirculation of GC B cells as a multilevel selection strategy for antibody maturation. ${ }^{170}$ This might be particulary true for IgA B-cell responses in GALT. In fact, there are GC in PP that host multiple B-cell clones and these polyclonal GC sites could allow for both T-cell-dependent and T-cell-independent B-cell responses. ${ }^{77}$ This way wild-type IgA gene sequences are mostly heavily mutated, while the IgA gene sequences from CD40- or T-cell-deficient mice largely lack mutations as these mice do not host GC in their GALT. ${ }^{35,86}$ Recently, we also found evidence that activated NP-specific B1-8 ${ }^{\text {hi }} \mathrm{GFP}^{+}$B cells isolated from PPs after adoptive transfer could enter already existing GC in the PPs of the recipient mouse provided that oral antigen was given $24 \mathrm{~h}$ prior to transfer. ${ }^{112}$ Hence, re-utilization of pre-existing GC in PP is a prime feature of the intricate induction of IgA B-cell responses in GALT and the reason why high quality SIgA antibodies are found at mucosal sites. ${ }^{171}$ This system operates at the gut level, but whether it also functions at other mucosal sites has not been investigated.

\section{MEMORY B CELLS AND LONG-LIVED PLASMA CELLS AFTER MUCOSAL IMMUNIZATION}

The ability to develop long-term B-cell memory and production of antigen-specific SIgA antibodies is pivotal to successful mucosal vaccination and it might be critical for homeostasis of the microbiota. ${ }^{12,172}$ However, this ability has been questioned as the longevity of protection after mucosal vaccination has been reported to be short-lived. ${ }^{173}$ Also, mono-colonization of germ-free mice with a commensal auxotrophic E. coli strain, i.e., dependent on nutrients not present in the mammalian host, established a reversible colonization of the gut, which failed to induce memory B cells. ${ }^{153}$ On the other hand, findings of mucosal memory B-cell development and long-lived plasma cells in mice after infection or oral immunizations have been 

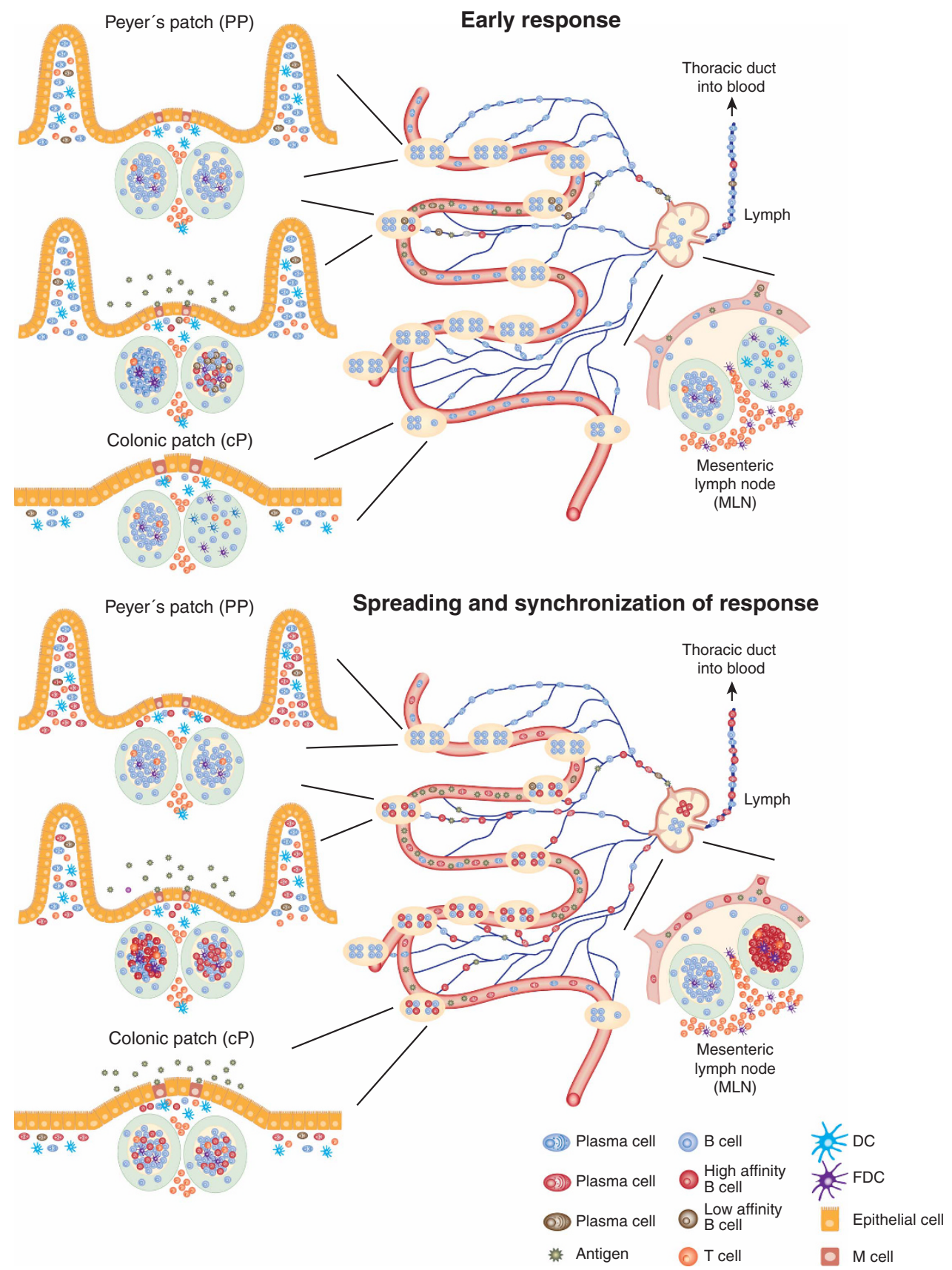

Figure 3 Spreading and synchronization of gut IgA responses. In the early response, B-cell activation occurs in GALT by direct contact with antigen and low affinity naïve $B$ cells undergo cell division in the B-cell follicle or the SED. The activated B cells next invade preexisting GC and continue to proliferate and mutate their Ig genes. Occasionally, high-affinity clones will arise in this process. Due to migration of these activated B cells out of the GC into the lymph at an early stage, and recirculation through the hemolymphatic cycle, the high-affinity B-cell clones will be disseminated to multiple PPs. Subsequent to additional antigen exposures in GC of multiple PPs, these high-affinity clones will be effectively selected and, eventually, an oligoclonal high-affinity IgA response will dominate the gut lamina propria response. Noteworthy, there appears to be a preference for the generation of memory $B$ cells over long-lived plasma cells in the early GC-phase and, hence, the memory pool will be more diverse and less affinity matured compared to the plasma cells after priming. In this way the pool of memory B cells has a broader binding-repertoire than the more epitope-restricted plasma cells, securing that long-term protection against infection can be maintained.

reported. ${ }^{174,175}$ For example, in adoptive transfer studies only memory B cells carrying gut homing markers were effective at producing IgA and protecting against rotavirus infection, while B cells without $\alpha_{4} \beta_{7}$ integrin produced specific IgG antibodies in serum, but did not protect against the infection. ${ }^{176}$ Moreover, using $\mathrm{CT}$ as an immunogen or $\mathrm{CT}$ as adjuvant with co-administered antigen, we and others have documented extensively that specific memory B cells and long-lived plasma cells are generated following mucosal immunization. ${ }^{142,177-182}$ Using next-generation sequencing (NGS) Pabst and co-workers ${ }^{12,86}$ have provided compelling evidence that the intestinal IgA repertoire accumulates highly expanded memory 
B-cell clones with many mutations with age and that each individual clone harbors unique CDR3 sequences. These unique gene sequences tend to remain stable and following a complete depletion of plasma cells they are reintroduced by activation of memory B cells resulting in an identical gut IgA plasma cell repertoire.

We have developed a specific system for detailed analysis of the IgA response after oral immunization with the hapten NP conjugated to CT (NP-CT) by using an adoptive transfer model in which NP-specific B1-8 ${ }^{\text {hi }} \mathrm{GFP}^{+}$B cells are injected into wild-type hosts before immunization. ${ }^{112}$ This enables us to visualize the development and maintenance of memory B cells after oral immunizations with NP-CT. Using this model we found that strong memory B-cell responses were developed in multiple tissues, including spleen, MLN and GALT. ${ }^{71}$ These cells were maintained for at least a year in the B-cell follicles of the spleen, lymph nodes and GALT despite a very low frequency among all $B$ cells (1/1000-10 000). A subsequent oral challenge immunization elicited a dramatic IgA plasma cell response in the gut $\mathrm{LP}$, reaching a magnitude of almost $15 \%$ of all IgA plasma cells within a week. Most surprisingly, whereas, NP-specific IgA cells in the intestinal LP and the bone marrow were clonally highly related, little clonal relatedness was found between long-lived plasma cells and memory B cells. Furthermore, an NGS analysis of IgA V-genes in long-lived plasma cells and memory B cells demonstrated in over 86,000 NP-specific sequences, more mutations and higher levels of affinity maturation in IgA-expressing long-lived plasma cells than in memory B cells. These observations suggest that memory B cells may leave $\mathrm{GC}$ reactions at an earlier time point than the long-lived plasma cells, an idea that is supported by a recent study from the Shlomchik laboratory. ${ }^{183}$ By contrast, following a challenge immunization 1 year later, boosted IgA memory B cells in PP and the resulting IgA plasma cells in the LP were oligoclonal, arguing for an effective selection and maturation process of memory B cells in secondary GC upon reactivation. ${ }^{71}$ Therefore, a secondary GC reaction appears critical to secure the production of high quality memory IgA antibodies in the gut LP. Indeed, a recent study by McHeyzer-Williams et al. ${ }^{184}$ demonstrated at the single cell level that BCR diversification can be reinitiated in switched-memory B cells in secondary GC. We believe our observation in PP is a good example of this notion.

Furthermore, NP-specific memory B cells following oral immunization resided in the B-cell follicles in spleen, MLN and GALT and these cells, similar to other mouse memory B cells, expressed CD80, PD-L2 and CD73. ${ }^{71,185,186}$ Upon adoptive transfer anti-NP IgA and IgG responses were recorded upon a challenge immunization. Memory $B$ cells expressed $\alpha_{4} \beta_{7}$ integrin and were $\operatorname{IgA}{ }^{+}$in $\mathrm{PP}$, whereas in other locations they were mostly $\operatorname{IgM}^{+}$. Upon reactivation, most activated memory B cells in PP did not re-express GL7, but nevertheless expanded and underwent strong clonal selection in GC with affinity maturation. Noteworthy, only reactivated memory B cells in PP, but not in spleen, up-regulated expression of CCR9 on the differentiating plasmablasts. Hence, memory B cells in the spleen did not contribute to the gut LP IgA plasma cell response and, therefore, it could be speculated that oral priming induces memory B cells distinct from those formed after systemic priming. This idea finds support in that $\mathrm{IgG}^{+}$memory B cells appear to depend on the T-bet transcription factor (Tbx21), whereas memory $\operatorname{IgA}{ }^{+} \mathrm{B}$ cells instead express $\mathrm{ROR} \alpha{ }^{187}$

Following oral immunization all memory B cells expressed CD73 in the GALT, which we propose is indicative of a PP GC origin, as few such cells are present in young CD40-deficient mice. ${ }^{71}$ As $\mathrm{CD} 73^{+} \mathrm{B}$ cells accumulate in PP with age it appears that both TD and TI antigens may drive this accumulation. Hence, we propose that $\mathrm{B}$ cells responding to gut TI antigens also acquire CD73 after passing through a GC. However, we still have only a weak perception of what proportion of gut IgA plasma cells in the LP are representing B cells reactive to TI antigens in a normal homeostatic intestine. ${ }^{188}$

\section{A PROPOSED MODEL OF GUT IGA B-CELL RESPONSES}

Because specific gut IgA responses are oligoclonal and essentially all gut LP IgA plasma cells in WT mice have acquired extensive SHM, activated B cells are likely to have passed through GC prior to migrating to the LP. ${ }^{35,86,189}$ These observations converge on the notion that activated B cells can re-utilize pre-existing GC in PP, which is central to explaining how gut IgA responses are synchronized and that even TI antigens will drive somatically mutated B-cell clones in the gut. ${ }^{87}$ By contrast, in CD40- and T-cell-deficient mice IgA CSR can occur, but SHM is not observed in the $\mathrm{IgV}_{\mathrm{H}^{-}}$-genes. ${ }^{35,86}$ Hence, IgA CSR does not strictly require GC formations in PP, but can occur at a GL7 ${ }^{\text {int }}$ stage, prior to GC maturation. ${ }^{35}$ This notion finds support in a recent study by Reboldi et al. which reported IgA CSR in the SED region of the PP where CD11b ${ }^{+}$ DC-B-cell interactions occur following CCR6-dependent migration to SED before entering the GC. ${ }^{55}$ Whether IgA CSR initiated in the SED region occurs in response to both TD and TI antigen is not known, but findings of strong IgA CSR in the absence of PP GC in CD40-deficient mice would support this idea. ${ }^{35,59}$ Reboldi and co-workers ${ }^{55}$ also provided experimental data to suggest that activated B cells could move in retrograde direction from the SED to the follicle. Accordingly, we recently observed a migratory pattern of activated $\mathrm{GFP}^{+}$ NP-specific B cells that support a role for SED during an ongoing response (Figure 4). We observed that responding $B$ cells were detected in the SED, in direct contact with $\mathrm{M}$ cells, enabling sampling of antigen and effective delivery of antigen to the follicle (unpublished observation). We also found that oral antigen needed to be given $24 \mathrm{~h}$ prior to adoptive transfer of activated PP B cells in order to observe their re-utilization of GC in recipient mice. ${ }^{112}$ This way access to antigen could be secured in the GC by B cells migrating from SED in a manner similar to the suggested movement of marginal zone $B$ cells in spleen and follicular B cells in lymph nodes. ${ }^{190,191}$ This role for B cells in antigen transport from SED to GC in PP could be a mechanism for controlling the response and restrict the specific B-cell response to PPs that have access to luminal antigen. This way a widespread infection would engage many PPs while a local 
infection would engage only a single or few PPs. Moreover, oral priming immunization preferentially activates $B$ cells in the proximal small intestine, while repeated oral immunizations engages also the distal PPs. ${ }^{112}$ Whereas activated B cells leave the proximal PPs at an early stage, they accumulate in distal PPs, but only when sufficient luminal antigen is present in distal PPs. This is achieved only after repeated oral immunizations. The expansion of activated B cells in more distal PPs appears to require expression of CD40, because B cells lacking CD40
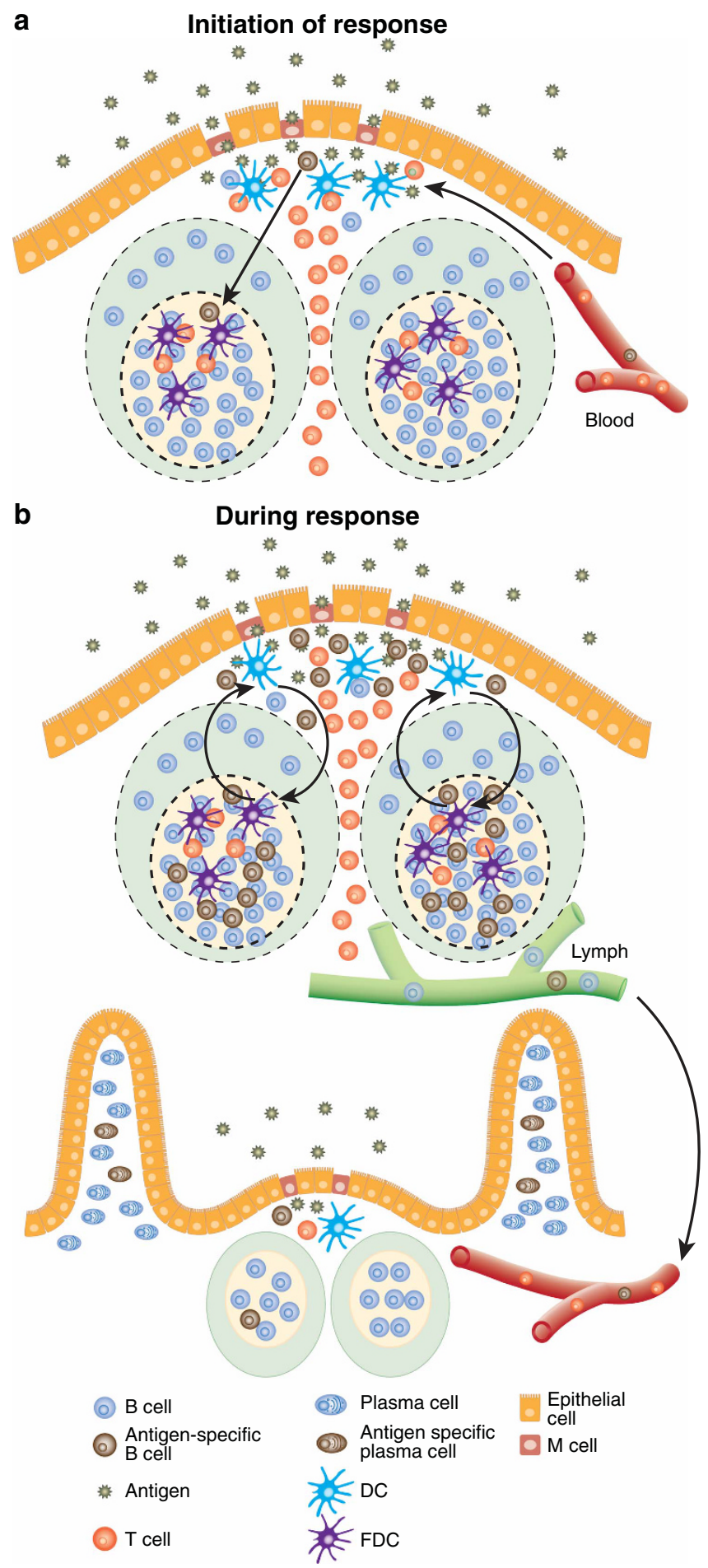

could not accumulate in pre-existing GC PPs (unpublished observation).

The majority of IgA-expressing plasma cells, those responding to TD antigens as well as to microbiota-derived TI antigens, are generated from B2 B cells in PP. ${ }^{38,192}$ Activated B cells enter GC before or after IgA CSR and next go through several rounds of proliferation and affinity maturation, as a consequence of extensive SHM, before seeding the LP. The function of mucosal immunity requires a highly developed distribution and synchronization system for IgA plasma cells to the effector sites. IgA responses are oligoclonal following immunization and clonally related IgA cells are distributed along the entire gut immune system, including both inductive and effector sites. ${ }^{112}$ The fact that GCs are constantly present in PPs allows antigenactivated memory B cells to enter already existing GC in multiple PPs and to undergo rapid expansion, further somatic Ig- $\mathrm{V}$ region hypermutations and extensive clonal selection. Despite small numbers of resting IgA memory B cells in PPs, an oral challenge immunization dramatically elicited an impressive gut LP response. ${ }^{71}$ We believe the reason for this is access to multiple sites for antigen-driven expansion of memory B cells and the ability to share expanding and affinity maturing memory B-cell clones. The plasticity of the IgA-inductive site in the PPs allows for the generation of memory B cells and longlived plasma cells that are clonally unrelated. In fact, by generating less mutated memory B cells that leave the GC early, before higher affinity plasma cells, a broader memory B-cell repertoire will guarantee better host protection in the long term. It can be envisioned that a broad memory B-cell repertoire is functionally important and could explain crossprotection against related pathogens, such as Vibrio cholerae and enterotoxigenic E. coli. ${ }^{193}$ Nevertheless, with the expanded knowledge about the regulation of gut IgA responses and long-term memory development in the GALT, chances are that future oral subcomponent vaccines can be made more effective. This will require better vaccine formulations and more effective mucosal adjuvants that can enhance activation of B cells in the GALT and which also sustain presence of antigen to support the clonal expansion and selection of $\mathrm{B}$ cells required for a high quality protective IgA repertoire. Prospects for such a development look favorable.

Figure 4 Movement of antigen-activated $B$ cells within the PP. (a) When B cells enter into PP they up-regulate expression of CCR6, and move towards the SED where they will be in close contact with $M$ cells and DCs, which activate TGF- $\beta$ production subsequent to the expression of $\alpha v \beta 8$, leading to IgA CSR. ${ }^{55}$ (b) In the GC, activated $B$ cells proliferate and affinity mature in an antigen-dependent selection process. To secure the presence of antigen in the GC, activated B cells intermittently down-modulate Bcl6 and upregulate CCR6. They can, thus, migrate from the GC to SED and acquire antigen from $M$ cells. B cells of many specificities can simultaneously traffic from GC to SED and back to the GC again, loading multiple antigens onto the FDC network as has been described for peripheral lymph nodes and spleen. ${ }^{191}$ These antigentransporting B cells will shuttle between the SED and the dark and light zone of the GC to support affinity maturation for as long as antigen is present in the lumen. Activated $B$ cells that circulate between multiple PPs also up-regulate CCR6 and move into SED to sample antigen before they re-utilize a pre-existing GC. 


\section{ACKNOWLEDGMENTS}

We thank Anneli Strömberg for preparing the images shown in Figures 1 and 2. Studies received generous funding from the Swedish Research Council, the Swedish Cancer Foundation, The Swedish Foundation for Strategic Research, Knut and Alice Wallenberg's Foundation, The Lundberg foundation, LUAALF funding and EU FP7 ITN UniVacFlu and INNOVATION-1, UNISEC projects.

\section{AUTHOR CONTRIBUTIONS}

The authors contributed equally to the writing of this review paper.

\section{DISCLOSURE}

The authors declared no conflict of interest.

c) 2017 Society for Mucosal Immunology

\section{REFERENCES}

1. Mestecky, J., Zikan, J. \& Butler, W.T. Immunoglobulin M and secretory immunoglobulin $\mathrm{A}$ : presence of a common polypeptide chain different from light chains. Science 171, 1163-1165 (1971).

2. Halpern, M.S. \& Koshland, M.E. Noval subunit in secretory IgA. Nature 228, 1276-1278 (1970).

3. Brandtzaeg, P. Secretory IgA: Designed for Anti-Microbial Defense. Front. Immunol. 4, 222 (2013).

4. Corthésy, B. Multi-faceted functions of secretory lgA at mucosal surfaces. Front. Immunol. 4, 185 (2013).

5. Blutt, S.E. \& Conner, M.E. The Gastrointestinal Frontier: IgA and Viruses. Front. Immunol. 4, 402 (2013).

6. Brandtzaeg, P. Induction of secretory immunity and memory at mucosal surfaces. Vaccine 25, 5467-5484 (2007).

7. Pabst, O., Cerovic, V. \& Hornef, M. Secretory IgA in the Coordination of Establishment and Maintenance of the Microbiota. Trends Immunol. 37, 287-296 (2016).

8. Moor, K. et al. High-avidity IgA protects the intestine by enchaining growing bacteria. Nature 544, 498-502 (2017).

9. Lycke, N. Recent progress in mucosal vaccine development: potential and limitations. Nat. Rev. Immunol. 12, 592-605 (2012).

10. Macpherson, A.J., Köller, Y. \& McCoy, K.D. The bilateral responsiveness between intestinal microbes and IgA. Trends Immunol. 36, 460-470 (2015).

11. Zeng, M.Y., Inohara, N. \& Nuñez, G. Mechanisms of inflammation-driven bacterial dysbiosis in the gut. Mucosal Immunol. 10, 18-26 (2017).

12. Lindner, C. et al. Diversification of memory B cells drives the continuous adaptation of secretory antibodies to gut microbiota. Nat. Immunol. 16, 880-888 (2015).

13. de Agüero, M.G. et al. The maternal microbiota drives early postnatal innate immune development. Science 351, 1296-1302 (2016).

14. Fransen, F. et al. BALB/C and C57BL/6 Mice Differ in Polyreactive IgA Abundance, which Impacts the Generation of Antigen-Specific IgA and Microbiota Diversity. Immunity 43, 527-540 (2015).

15. Zagato, E., Mazzini, E. \& Rescigno, M. The variegated aspects of Immunoglobulin A. Immunol. Lett. 178, 45-49 (2016).

16. Spencer, J. \& Sollid, L.M. The human intestinal B-cell response. Mucosal Immunol. 9, 1113-1124 (2016).

17. Brandtzaeg, P., Kiyono, H., Pabst, R. \& Russell, M.W. Terminology: nomenclature of mucosa-associated lymphoid tissue. Mucosal Immunol. 1, 31-37 (2008).

18. Ruane, D. et al. Lung dendritic cells induce migration of protective Tcells to the gastrointestinal tract. J. Exp. Med. 210, 1871-1888 (2013).

19. Hill, D.A. \& Artis, D. Intestinal bacteria and the regulation of immune cell homeostasis. Annu. Rev. Immunol. 28, 623-667 (2010).

20. Ohno, H. Intestinal M cells. J. Biochem. 159, 151-160 (2016).

21. Kanaya, T. et al. The Ets transcription factor Spi-B is essential for the differentiation of intestinal microfold cells. Nat. Immunol. 13, 729-736 (2012).

22. Sato, S. et al. Transcription factor Spi-B-dependent and -independent pathways for the development of Peyer's patch M cells. Mucosal Immunol. 6, 838-846 (2013).
23. Mabbott, N.A., Donaldson, D.S., Ohno, H., Williams, I.R. \& Mahajan, A. Microfold (M) cells: important immunosurveillance posts in the intestinal epithelium. Mucosal Immunol. 6, 666-677 (2013).

24. Nagashima, K. et al. Identification of subepithelial mesenchymal cells that induce IgA and diversify gut microbiota. Nat. Immunol. 9, 618 (2017).

25. Rios, D. et al. Antigen sampling by intestinal $M$ cells is the principal pathway initiating mucosal lgA production to commensal enteric bacteria. Mucosal Immunol. 9, 907-916 (2016).

26. McDole, J.R. et al. Goblet cells deliver luminal antigen to CD103(+) dendritic cells in the small intestine. Nature 483, 345-349 (2012).

27. Shan, M. et al. Mucus enhances gut homeostasis and oral tolerance by delivering immunoregulatory signals. Science 342, 447-453 (2013).

28. Johansson, M.E.V. \& Hansson, G.C. Immunological aspects of intestinal mucus and mucins. Nat. Rev. Immunol. 16, 639-649 (2016).

29. Chieppa, M., Rescigno, M., Huang, A.Y.C. \& Germain, R.N. Dynamic imaging of dendritic cell extension into the small bowel lumen in response to epithelial cell TLR engagement. J. Exp. Med. 203, 2841-2852 (2006).

30. Farache, J. et al. Luminal bacteria recruit CD103 + dendritic cells into the intestinal epithelium to sample bacterial antigens for presentation. Immunity 38, 581-595 (2013).

31. Mazzini, E., Massimiliano, L., Penna, G. \& Rescigno, M. Oral tolerance can be established via gap junction transfer of fed antigens from CX3CR $1^{+}$ macrophages to $\mathrm{CD}_{103}{ }^{+}$dendritic cells. Immunity 40, 248-261 (2014).

32. Craig, S.W. \& Cebra, J.J. Peyer's patches: an enriched source of precursors for IgA-producing immunocytes in the rabbit. J. Exp. Med. 134, 188-200 (1971).

33. Dohi, T. et al. Hapten-induced colitis is associated with colonic patch hypertrophy and T helper cell 2-type responses. J. Exp. Med. 189 1169-1180 (1999)

34. O'Leary, A.D. \& Sweeney, E.C. Lymphoglandular complexes of the colon: structure and distribution. Histopathology 10, 267-283 (1986).

35. Bergqvist, P., Stensson, A., Lycke, N.Y. \& Bemark, M. Tcell-independent IgA class switch recombination is restricted to the GALT and occurs prior to manifest germinal center formation. J. Immunol. 184, 3545-3553 (2010).

36. Knoop, K.A. \& Newberry, R.D. Isolated lymphoid follicles are dynamic reservoirs for the induction of intestinal IgA. Front. Immunol. 3, 84 (2012).

37. Baptista, A.P. et al. Colonic patch and colonic SILT development are independent and differentially regulated events. Mucosal Immunol. 6 , 511-521 (2013).

38. Bemark, M., Boysen, P. \& Lycke, N.Y. Induction of gut IgA production through T cell-dependent and T cell-independent pathways. Ann. NY Acad. Sci. 1247, 97-116 (2012).

39. Lorenz, R.G., Chaplin, D.D., McDonald, K.G., McDonough, J.S. \& Newberry, R.D. Isolated lymphoid follicle formation is inducible and dependent upon lymphotoxin-sufficient B lymphocytes, lymphotoxin beta receptor, and TNF receptor I function. J. Immunol. 170, 5475-5482 (2003).

40. Pabst, O. et al. Cryptopatches and isolated lymphoid follicles: dynamic lymphoid tissues dispensable for the generation of intraepithelia lymphocytes. Eur. J. Immunol. 35, 98-107 (2005).

41. Masahata, K. et al. Generation of colonic IgA-secreting cells in the caecal patch. Nat. Commun. 5, 3704 (2014).

42. Lécuyer, E. et al. Segmented filamentous bacterium uses secondary and tertiary lymphoid tissues to induce gut IgA and specific $T$ helper 17 cell responses. Immunity 40, 608-620 (2014).

43. Lochner, M. et al. Microbiota-induced tertiary lymphoid tissues aggravate inflammatory disease in the absence of RORgamma $t$ and $\mathrm{LTi}$ cells. J. Exp. Med. 208, 125-134 (2011).

44. Hahn, A., Thiessen, N., Pabst, R., Buettner, M. \& Bode, U. Mesenteric lymph nodes are not required for an intestinal immunoglobulin A response to oral cholera toxin. Immunology 129, 427-436 (2010).

45. Pabst, O. New concepts in the generation and functions of IgA. Nat. Rev. Immunol. 12, 821-832 (2012).

46. Pabst, O. \& Mowat, A.M. Oral tolerance to food protein. Mucosal Immunol. 5, 232-239 (2012).

47. Houston, S.A. et al. The lymph nodes draining the small intestine and colon are anatomically separate and immunologically distinct. Mucosal Immunol. 9, 468-478 (2016). 
48. Macpherson, A.J., Mccoy, K.D., Johansen, F.-E. \& Brandtzaeg, P. The immune geography of IgA induction and function. Mucosal Immunol. 1, 11-22 (2008).

49. Kuklin, N.A. et al. Protective intestinal anti-rotavirus B cell immunity is dependent on alpha 4 beta 7 integrin expression but does not require lgA antibody production. J. Immunol. 166, 1894-1902 (2001).

50. Hieshima, K. et al. CC chemokine ligands 25 and 28 play essential roles in intestinal extravasation of IgA antibody-secreting cells. J. Immunol. 173, 3668-3675 (2004).

51. Pabst, O. et al. Chemokine receptor CCR9 contributes to the localization of plasma cells to the small intestine. J. Exp. Med. 199, 411-416 (2004).

52. Feng, N. et al. Redundant role of chemokines CCL25/TECK and CCL28/ MEC in IgA + plasmablast recruitment to the intestinal lamina propria after rotavirus infection. J. Immunol. 176, 5749-5759 (2006).

53. Shreedhar, V.K., Kelsall, B.L. \& Neutra, M.R. Cholera toxin induces migration of dendritic cells from the subepithelial dome region to $T$ - and B-cell areas of Peyer's patches. Infect. Immun. 71, 504-509 (2003).

54. Reboldi, A. \& Cyster, J.G. Peyer's patches: organizing B-cell responses at the intestinal frontier. Immunol. Rev. 271, 230-245 (2016).

55. Reboldi, A. et al. IgA production requires $B$ cell interaction with subepithelial dendritic cells in Peyer's patches. Science 352, aaf4822-aaf4822 (2016).

56. Tezuka, H. et al. Regulation of IgA production by naturally occurring TNF/ iNOS-producing dendritic cells. Nature 448, 929-933 (2007).

57. Tezuka, H. et al. Prominent role for plasmacytoid dendritic cells in mucosal T cell-independent IgA induction. Immunity 34, 247-257 (2011).

58. Uematsu, S. et al. Regulation of humoral and cellular gut immunity by lamina propria dendritic cells expressing Toll-like receptor 5 . Nat. Immunol. 9, 769-776 (2008).

59. Bergqvist, P., Gärdby, E., Stensson, A., Bemark, M. \& Lycke, N.Y. Gut IgA class switch recombination in the absence of CD40 does not occur in the lamina propria and is independent of germinal centers. J. Immunol. 177, 7772-7783 (2006).

60. Shikina, T. et al. IgA class switch occurs in the organized nasopharynxand gut-associated lymphoid tissue, but not in the diffuse lamina propria of airways and gut. J. Immunol. 172, 6259-6264 (2004).

61. Fagarasan, S., Kinoshita, K., Muramatsu, M., Ikuta, K. \& Honjo, T. In situ class switching and differentiation to IgA-producing cells in the gut lamina propria. Nature 413, 639-643 (2001).

62. He, B. et al. Intestinal bacteria trigger Tcell-independent immunoglobulin A(2) class switching by inducing epithelial-cell secretion of the cytokine APRIL. Immunity 26, 812-826 (2007).

63. Boursier, L., Gordon, J.N., Thiagamoorthy, S., Edgeworth, J.D. \& Spencer, J. Human intestinal IgA response is generated in the organized gut-associated lymphoid tissue but not in the lamina propria. Gastroenterology 128, 1879-1889 (2005).

64. Shen, H.M. et al. Expression of AID transgene is regulated in activated $B$ cells but not in resting B cells and kidney. Mol. Immunol. 45, 1883-1892 (2008).

65. Tangye, S.G. \& Hodgkin, P.D. Divide and conquer: the importance of cell division in regulating B-cell responses. Immunology 112, 509-520 (2004).

66. Kinoshita, K., Harigai, M., Fagarasan, S., Muramatsu, M. \& Honjo, T. A hallmark of active class switch recombination: transcripts directed by I promoters on looped-out circular DNAs. Proc. Natl Acad. Sci. USA 98, 12620-12623 (2001)

67. Crouch, E.E. et al. Regulation of AID expression in the immune response. J. Exp. Med. 204, 1145-1156 (2007).

68. Fagarasan, S., Kawamoto, S., Kanagawa, O. \& Suzuki, K. Adaptive immune regulation in the gut: Tcell-dependent and Tcell-independent IgA synthesis. Annu. Rev. Immunol. 28, 243-273 (2010).

69. Yamamoto, M. et al. Role of gut-associated lymphoreticular tissues in antigen-specific intestinal IgA immunity. J. Immunol. 173, 762-769 (2004).

70. Husband, A.J. \& Gowans, J.L. The origin and antigen-dependent distribution of IgA-containing cells in the intestine. J. Exp. Med. 148, 1146-1160 (1978).

71. Bemark, M. et al. Limited clonal relatedness between gut IgA plasma cells and memory B cells after oral immunization. Nat. Commun. 7, 12698 (2016).

72. Lycke, N.Y. \& Bemark, M. The role of Peyer's patches in synchronizing gut IgA responses. Front. Immunol. 3, 329 (2012).
73. Tangye, S. \& Tarlinton, D. Memory B cells: effectors of long-lived immune responses. Eur. J. Immunol. 39, 2065-2075 (2009).

74. Crotty, S. Follicular helper CD4 T cells (TFH). Annu. Rev. Immunol. 29, 621-663 (2011).

75. Victora, G.D. \& Nussenzweig, M.C. Germinal centers. Annu. Rev. Immunol. 30, 429-457 (2012).

76. Victora, G.D. et al. Germinal center dynamics revealed by multiphoton microscopy with a photoactivatable fluorescent reporter. Cell 143, 592-605 (2010).

77. Tas, J.M.J. et al. Visualizing antibody affinity maturation in germinal centers. Science 351, 1048-1054 (2016).

78. Heesters, B.A., Myers, R.C. \& Carroll, M.C. Follicular dendritic cells: dynamic antigen libraries. Nat. Rev. Immunol. 14, 495-504 (2014).

79. Han, S., Zheng, B., Dal Porto, J. \& Kelsoe, G. In situ studies of the primary immune response to (4-hydroxy-3-nitrophenyl)acetyl. IV. Affinity-dependent, antigen-driven B cell apoptosis in germinal centers as a mechanism for maintaining self-tolerance. J. Exp. Med. 182, 1635-1644 (1995).

80. Casola, S. et al. B cell receptor signal strength determines B cell fate. Nat. Immunol. 5, 317-327 (2004).

81. Stavnezer, J., Guikema, J.E.J. \& Schrader, C.E. Mechanism and reguIation of class switch recombination. Annu. Rev. Immunol. 26, 261-292 (2008).

82. Tsuji, M. et al. Requirement for lymphoid tissue-inducer cells in isolated follicle formation and T cell-independent immunoglobulin A generation in the gut. Immunity 29, 261-271 (2008).

83. Di Noia, J.M. \& Neuberger, M.S. Molecular mechanisms of antibody somatic hypermutation. Annu. Rev. Biochem. 76, 1-22 (2007).

84. Muramatsu, M. et al. Class switch recombination and hypermutation require activation-induced cytidine deaminase (AID), a potential RNA editing enzyme. Cell 102, 553-563 (2000).

85. Muramatsu, M. et al. Specific expression of activation-induced cytidine deaminase (AID), a novel member of the RNA-editing deaminase family in germinal center B cells. J. Biol. Chem. 274, 18470-18476 (1999).

86. Lindner, C. et al. Age, microbiota, and T cells shape diverse individual IgA repertoires in the intestine. J. Exp. Med. 209, 365-377 (2012).

87. Kauffman, R.C. et al. Single-cell analysis of the plasmablast response to vibrio cholerae demonstrates expansion of cross-reactive memory $\mathrm{B}$ cells. MBio 7, e02021-16 (2016).

88. Stavnezer, J. \& Schrader, C.E. IgH chain class switch recombination: mechanism and regulation. J. Immunol. 193, 5370-5378 (2014).

89. Kurosaki, T., Shinohara, H. \& Baba, Y. B cell signaling and fate decision. Annu. Rev. Immunol. 28, 21-55 (2010).

90. Stavnezer, J. \& Kang, J. The surprising discovery that TGF beta specifically induces the IgA class switch. J. Immunol. 182, 5-7 (2009).

91. Cazac, B.B. \& Roes, J. TGF-beta receptor controls B cell responsiveness and induction of IgA in vivo. Immunity 13, 443-451 (2000).

92. Borsutzky, S., Cazac, B.B., Roes, J. \& Guzmán, C.A. TGF-beta receptor signaling is critical for mucosal IgA responses. J. Immunol. 173, 3305-3309 (2004).

93. Travis, M.A. \& Sheppard, D. TGF- $\beta$ Activation and Function in Immunity. Annu. Rev. Immunol. 32, 51-82 (2014).

94. Mora, J.R. et al. Generation of gut-homing IgA-secreting B cells by intestinal dendritic cells. Science 314, 1157-1160 (2006).

95. Tsuji, M. et al. Preferential generation of follicular B helper T cells from Foxp3 + Tcells in gut Peyer's patches. Science 323, 1488-1492 (2009).

96. Castigli, E. et al. TACl and BAFF-R mediate isotype switching in B cells. J. Exp. Med. 201, 35-39 (2005).

97. Pasare, C. \& Medzhitov, R. Control of B-cell responses by Toll-like receptors. Nature 438, 364-368 (2005).

98. von Bülow, G.U., van Deursen, J.M. \& Bram, R.J. Regulation of the T-independent humoral response by TACI. Immunity 14, 573-582 (2001).

99. Yan, M. et al. Activation and accumulation of B cells in TACl-deficient mice. Nat. Immunol. 2, 638-643 (2001).

100. Varfolomeev, E. et al. APRIL-deficient mice have normal immune system development. Mol. Cell. Biol. 24, 997-1006 (2004).

101. Castigli, E. et al. Impaired IgA class switching in APRIL-deficient mice. Proc. Natl Acad. Sci. USA 101, 3903-3908 (2004).

102. Rickert, R.C., Jellusova, J. \& Miletic, A.V. Signaling by the tumor necrosis factor receptor superfamily in B-cell biology and disease. Immunol. Rev. 244, 115-133 (2011). 
103. Mora, J.R. \& von Andrian, U.H. Role of retinoic acid in the imprinting of gut-homing IgA-secreting cells. Semin. Immunol. 21, 28-35 (2009).

104. Park, M.-H., Park, S.-R., Lee, M.-R., Kim, Y.-H. \& Kim, P.-H. Retinoic acid induces expression of Ig germ line $\alpha$ transcript, an lgA isotype switching indicative, through retinoic acid receptor. Genes Genome 33, 83-88 (2011).

105. Kaufman, D.R. et al. Vitamin A deficiency impairs vaccine-elicited gastrointestinal immunity. J. Immunol. 187, 1877-1883 (2011).

106. Cao, A.T. et al. Interleukin (IL)-21 promotes intestinal IgA response to microbiota. Mucosal Immunol. 8, 1072-1082 (2015).

107. Fröhlich, A. et al. IL-21 receptor signaling is integral to the development of Th2 effector responses in vivo. Blood 109, 2023-2031 (2007).

108. Cao, A.T., Yao, S., Gong, B., Elson, C.O. \& Cong, Y. Th17 cells upregulate polymeric Ig receptor and intestinal IgA and contribute to intestinal homeostasis. J. Immunol. 189, 4666-4673 (2012).

109. Datta, S.K. et al. Mucosal adjuvant activity of cholera toxin requires Th17 cells and protects against inhalation anthrax. Proc. Natl Acad. Sci. USA 107, 10638-10643 (2010).

110. Seo, G.-Y., Youn, J. \& Kim, P.-H. IL-21 ensures TGF-beta 1-induced IgA isotype expression in mouse Peyer's patches. J. Leukoc. Biol. 85, 744-750 (2009).

111. Suzuki, K. et al. The sensing of environmental stimuli by follicular dendritic cells promotes immunoglobulin A generation in the gut. Immunity $33,71-$ 83 (2010).

112. Bergqvist, P. et al. Re-utilization of germinal centers in multiple Peyer's patches results in highly synchronized, oligoclonal, and affinity-matured gut IgA responses. Mucosal Immunol. 6, 122-135 (2013).

113. Zhang, Y., Garcia-Ibanez, L. \& Toellner, K.-M. Regulation of germinal center B-cell differentiation. Immunol. Rev. 270, 8-19 (2016).

114. Woof, J.M. \& Russell, M.W. Structure and function relationships in IgA. Mucosal Immunol. 4, 590-597 (2011).

115. Kurita, N., Honda, S.-I. \& Shibuya, A. Increased serum IgA in Fcal $\mu R$-deficient mice on the $(129 \times$ C57BL/6) F1 genetic background. Mol. Immunol. 63, 367-372 (2015).

116. Zhang, Y. et al. Germinal center B cells govern their own fate via antibody feedback. J. Exp. Med. 210, 457-464 (2013).

117. Kim, S.-H., Kim, Y.N. \& Jang, Y.-S. Cutting Edge: LL-37-Mediated Formyl Peptide Receptor-2 Signaling in Follicular Dendritic Cells Contributes to B Cell Activation in Peyer's Patch Germinal Centers. J. Immunol. 198, 629-633 (2017).

118. Hou, S. et al. Follicular dendritic cell secreted protein FDC-SP controls IgA production. Mucosal Immunol. 7, 948-957 (2014).

119. Shang, L. et al. Toll-like receptor signaling in small intestinal epithelium promotes B-cell recruitment and IgA production in lamina propria. Gastroenterology 135, 529-538 (2008).

120. Danisch, S. etal. CD226 interaction with CD155 impacts on retention and negative selection of CD8 positive thymocytes as well as $T$ cell differentiation to follicular helper cells in Peyer's Patches. Immunobiology 218, 152-158 (2013).

121. Hashiguchi, M. et al. Naïve CD4 + T cells of Peyer's patches produce more IL-6 than those of spleen in response to antigenic stimulation. Immunol. Lett. 141, 109-115 (2011).

122. Seth, S. et al. Abundance of follicular helper $T$ cells in Peyer's patches is modulated by CD155. Eur. J. Immunol. 39, 3160-3170 (2009).

123. Zhu, Y., Zou, L. \& Liu, Y.-C. T follicular helper cells, T follicular regulatory cells and autoimmunity. Int. Immunol. 28, 173-179 (2016).

124. Shulman, Z. et al. Dynamic signaling by $T$ follicular helper cells during germinal center B cell selection. Science 345, 1058-1062 (2014).

125. Noelle, R.J. et al. A 39-kDa protein on activated helper Tcells binds CD40 and transduces the signal for cognate activation of B cells. Proc. Natl Acad. Sci. USA 89, 6550-6554 (1992).

126. Vinuesa, C.G., Linterman, M.A., Yu, D. \& MacLennan, I.C.M. Follicular Helper T Cells. Annu. Rev. Immunol. 34, 335-368 (2016).

127. Sage, P.T. \& Sharpe, A.H. T follicular regulatory cells. Immunol. Rev. 271, 246-259 (2016).

128. Kawamoto, S. et al. Foxp3(+) Tcells regulate immunoglobulin a selection and facilitate diversification of bacterial species responsible for immune homeostasis. Immunity 41, 152-165 (2014).
129. Aloulou, M. et al. Follicular regulatory $T$ cells can be specific for the immunizing antigen and derive from naive Tcells. Nat. Commun. 7, 10579 (2016).

130. Wu, H., Xie, M.M., Liu, H. \& Dent, A.L. Stat3 Is Important for Follicular Regulatory T Cell Differentiation. PLOS ONE 11, e0155040 (2016).

131. Sage, P.T. et al. Suppression by TFR cells leads to durable and selective inhibition of B cell effector function. Nat. Immunol. 17, 1436-1446 (2016).

132. Kawamoto, S. et al. The inhibitory receptor PD-1 regulates IgA selection and bacterial composition in the gut. Science 336, 485-489 (2012).

133. Hirota, K. et al. Plasticity of Th17 cells in Peyer's patches is responsible for the induction of T cell-dependent IgA responses. Nat. Immunol. 14, 372-379 (2013).

134. Brucklacher-Waldert, V., Carr, E.J., Linterman, M.A. \& Veldhoen, M. Cellular plasticity of CD4 + Tcells in the intestine. Front. Immunol. 5, 488 (2014).

135. Cong, Y., Feng, T., Fujihashi, K., Schoeb, T.R. \& Elson, C.O. A dominant, coordinated T regulatory cell-IgA response to the intestinal microbiota. Proc. Natl Acad. Sci. USA 106, 19256-19261 (2009).

136. Vendetti, S. et al. Polyclonal Treg cells enhance the activity of a mucosal adjuvant. Immunol. Cell Biol. 88, 698-706 (2010).

137. León, B., Bradley, J.E., Lund, F.E., Randall, T.D. \& Ballesteros-Tato, A. FoxP3 + regulatory T cells promote influenza-specific Tfh responses by controlling IL-2 availability. Nat. Commun. 5, 3495 (2014).

138. Ballesteros-Tato, A. et al. Interleukin-2 inhibits germinal center formation by limiting $T$ follicular helper cell differentiation. Immunity $36,847-856$ (2012).

139. Johnston, R.J., Choi, Y.S., Diamond, J.A., Yang, J.A. \& Crotty, S. STAT5 is a potent negative regulator of TFH cell differentiation. J. Exp. Med. 209, 243-250 (2012).

140. Oestreich, K.J., Mohn, S.E. \& Weinmann, A.S. Molecular mechanisms that control the expression and activity of Bcl-6 in TH1 cells to regulate flexibility with a TFH-like gene profile. Nat. Immunol. 13, 405-411 (2012).

141. Ugur, M., Schulz, O., Menon, M.B., Krueger, A. \& Pabst, O. Resident $\mathrm{CD} 4+\mathrm{T}$ cells accumulate in lymphoid organs after prolonged antigen exposure. Nat. Commun. 5, 4821 (2014).

142. Lemke, A. et al. Long-lived plasma cells are generated in mucosal immune responses and contribute to the bone marrow plasma cell pool in mice. Mucosal Immunol. 9, 83-97 (2016).

143. Chu, V.T. et al. Eosinophils promote generation and maintenance of immunoglobulin-a-expressing plasma cells and contribute to gut immune homeostasis. Immunity 40, 582-593 (2014).

144. Jung, Y. et al. IL-1 $\beta$ in eosinophil-mediated small intestinal homeostasis and IgA production. Mucosal Immunol. 8, 930-942 (2015).

145. Berek, C. Eosinophils: important players in humoral immunity. Clin. Exp. Immunol. 183, 57-64 (2016).

146. Sutherland, D.B., Suzuki, K. \& Fagarasan, S. Fostering of advanced mutualism with gut microbiota by Immunoglobulin A. Immunol. Rev. 270, 20-31 (2016).

147. Bos, N.A. et al. Serum immunoglobulin levels and naturally occurring antibodies against carbohydrate antigens in germ-free BALB/c mice fed chemically defined ultrafiltered diet. Eur. J. Immunol. 19, 2335-2339 (1989).

148. Talham, G.L., Jiang, H.Q., Bos, N.A. \& Cebra, J.J. Segmented filamentous bacteria are potent stimuli of a physiologically normal state of the murine gut mucosal immune system. Infect. Immun. 67, 1992-2000 (1999).

149. Ivanov, I.I. et al. Induction of intestinal Th17 cells by segmented filamentous bacteria. Cell 139, 485-498 (2009).

150. Gaboriau-Routhiau, V. et al. The key role of segmented filamentous bacteria in the coordinated maturation of gut helper $\mathrm{T}$ cell responses. Immunity 31, 677-689 (2009).

151. Schnupf, P. et al. Growth and host interaction of mouse segmented filamentous bacteria in vitro. Nature 520, 99-103 (2015).

152. Obata, T. et al. Indigenous opportunistic bacteria inhabit mammalian gutassociated lymphoid tissues and share a mucosal antibody-mediated symbiosis. Proc. Natl. Acad. Sci. USA 107, 7419-7424 (2010).

153. Hapfelmeier, S. et al. Reversible microbial colonization of germ-free mice reveals the dynamics of IgAimmune responses. Science 328, 1705-1709 (2010). 
154. Kernbauer, E., Ding, Y. \& Cadwell, K. An enteric virus can replace the beneficial function of commensal bacteria. Nature 516, 94-98 (2014).

155. Kim, M., Qie, Y., Park, J. \& Kim, C.H. Gut Microbial Metabolites Fuel Host Antibody Responses. Cell Host Microbe 20, 202-214 (2016).

156. Macpherson, A.J. et al. A primitive T cell-independent mechanism of intestinal mucosal IgA responses to commensal bacteria. Science $\mathbf{2 8 8}$, 2222-2226 (2000).

157. Macpherson, A.J. \& Uhr, T. Induction of protective IgA by intestinal dendritic cells carrying commensal bacteria. Science 303, 1662-1665 (2004).

158. Bunker, J.J. et al. Innate and Adaptive Humoral Responses Coat Distinct Commensal Bacteria with Immunoglobulin A. Immunity 43, 541-553 (2015).

159. Palm, N.W. et al. Immunoglobulin A coating identifies colitogenic bacteria in inflammatory bowel disease. Cell 158, 1000-1010 (2014).

160. Suzuki, K. et al. Aberrant expansion of segmented filamentous bacteria in IgA-deficient gut. Proc. Natl Acad. Sci. USA 101, 1981-1986 (2004).

161. Wei, M. et al. Mice carrying a knock-in mutation of Aicda resulting in a defect in somatic hypermutation have impaired gut homeostasis and compromised mucosal defense. Nat. Immunol. 12, 264-270 (2011).

162. Rogier, E.W. et al. Secretory antibodies in breast milk promote long-term intestinal homeostasis by regulating the gut microbiota and host gene expression. Proc. Natl Acad. Sci. USA 111, 3074-3079 (2014).

163. Peterson, D.A., McNulty, N.P., Guruge, J.L. \& Gordon, J.I. IgA response to symbiotic bacteria as a mediator of gut homeostasis. Cell Host Microbe 2 , 328-339 (2007).

164. Kramer, D.R. \& Cebra, J.J. Early appearance of 'natural' mucosal IgA responses and germinal centers in suckling mice developing in the absence of maternal antibodies. J. Immunol. 154, 2051-2062 (1995).

165. Harris, N.L. et al. Mechanisms of neonatal mucosal antibody protection. J. Immunol. 177, 6256-6262 (2006).

166. Kau, A.L. et al. Functional characterization of IgA-targeted bacterial taxa from undernourished Malawian children that produce diet-dependent enteropathy. Sci. Transl. Med. 7, 276ra24-276ra24 (2015).

167. Spor, A., Koren, O. \& Ley, R. Unravelling the effects of the environment and host genotype on the gut microbiome. Nat. Rev. Microbiol. 9, 279290 (2011).

168. De Silva, N.S. \& Klein, U. Dynamics of B cells in germinal centres. Nat. Rev. Immunol. 15, 137-148 (2015).

169. Mesin, L., Ersching, J. \& Victora, G.D. Germinal center B cell dynamics. Immunity 45, 471-482 (2016).

170. Or-Guil, M., Wittenbrink, N., Weiser, A.A. \& Schuchhardt, J. Recirculation of germinal center B cells: a multilevel selection strategy for antibody maturation. Immunol. Rev. 216, 130-141 (2007).

171. Mantis, N.J., Rol, N. \& Corthesy, B. Secretory IgA's complex roles in immunity and mucosal homeostasis in the gut. Mucosal Immunol. 4, 603611 (2011).

172. Czerkinsky, C. \& Holmgren, J. Vaccines against enteric infections for the developing world. Philos. Trans. R. Soc. Lond. B Biol. Sci. 370, 20150142-20150142 (2015).

173. Cerutti, A. Immunology. IgA changes the rules of memory. Science $\mathbf{3 2 8}$, 1646-1647 (2010).

174. Burns, J.W. etal. Analyses of homologous rotavirus infection in the mouse model. Virology 207, 143-153 (1995).

175. McNeal, M.M. \& Ward, R.L. Long-term production of rotavirus antibody and protection against reinfection following a single infection of neonatal mice with murine rotavirus. Virology 211, 474-480 (1995).
176. Williams, M.B. et al. The memory B cell subset responsible for the secretory IgA response and protective humoral immunity to rotavirus expresses the intestinal homing receptor, alpha4beta7. J. Immunol. 161, 4227-4235 (1998).

177. Lycke, N., Hellström, U. \& Holmgren, J. Circulating cholera antitoxin memory cells in the blood one year after oral cholera vaccination in humans. Scand. J. Immunol. 26, 207-211 (1987).

178. Lycke, N. \& Holmgren, J. Long-term cholera antitoxin memory in the gut can be triggered to antibody formation associated with protection within hours of an oral challenge immunization. Scand. J. Immunol. 25, 407-412 (1987).

179. Lycke, N. \& Holmgren, J. Adoptive transfer of gut mucosal antitoxin memory by isolated B cells 1 year after oral immunization with cholera toxin. Infect. Immun. 57, 1137-1141 (1989).

180. Vajdy, M. \& Lycke, N. Stimulation of antigen-specific T- and B-cell memory in local as well as systemic lymphoid tissues following oral immunization with cholera toxin adjuvant. Immunology 80, 197-203 (1993).

181. Vajdy, M. \& Lycke, N. Mucosal memory B cells retain the ability to produce IgM antibodies 2 years after oral immunization. Immunology 86, 336-342 (1995).

182. Lycke, N. \& Bemark, M. Mucosal adjuvants and long-term memory development with special focus on CTA1-DD and other ADP-ribosylating toxins. Mucosal Immunol. 3, 556-566 (2010).

183. Weisel, F.J., Zuccarino-Catania, G.V., Chikina, M. \& Shlomchik, M.J. A temporal switch in the germinal center determines differential output of memory B and plasma cells. Immunity 44, 116-130 (2016).

184. McHeyzer-Williams, L.J., Milpied, P.J., Okitsu, S.L. \& McHeyzer-Williams, M.G. Class-switched memory B cells remodel BCRs within secondary germinal centers. Nat. Immunol. 16, 296-305 (2015).

185. Anderson, S.M., Tomayko, M.M., Ahuja, A., Haberman, A.M. \& Shlomchik, M.J. New markers for murine memory B cells that define mutated and unmutated subsets. J. Exp. Med. 204, 2103-2114 (2007).

186. Bemark, M. et al. A unique role of the cholera toxin A1-DD adjuvant for long-term plasma and memory B cell development. J. Immunol. 186, 1399-1410 (2011).

187. Wang, N.S. et al. Divergent transcriptional programming of class-specific B cell memory by T-bet and ROR $\alpha$. Nat. Immunol. 13, 604-611 (2012).

188. Benckert, J. et al. The majority of intestinal $\lg A+$ and $\lg G+$ plasmablasts in the human gut are antigen-specific. J. Clin. Invest. 121, 1946-1955 (2011).

189. Barone, F. et al. IgA-producing plasma cells originate from germinal centers that are induced by B-cell receptor engagement in humans. Gastroenterology 140, 947-956 (2011).

190. Cinamon, G., Zachariah, M.A., Lam, O.M., Foss, F.W. \& Cyster, J.G. Follicular shuttling of marginal zone $B$ cells facilitates antigen transport. Nat. Immunol. 9, 54-62 (2008).

191. Batista, F.D. \& Harwood, N.E. The who, how and where of antigen presentation to B cells. Nat. Rev. Immunol. 9, 15-27 (2009).

192. Thurnheer, M.C., Zuercher, A.W., Cebra, J.J. \& Bos, N.A. B1 cells contribute to serum IgM, but not to intestinal lgA, production in gnotobiotic Ig allotype chimeric mice. J. Immunol. 170, 4564-4571 (2003).

193. Clemens, J.D. et al. Cross-protection by B subunit-whole cell cholera vaccine against diarrhea associated with heat-labile toxin-producing enterotoxigenic Escherichia coli: results of a large-scale field trial. J. Infect. Dis. 158, 372-377 (1988).

194. Kijani, S. et al. Filter-dense multicolor microscopy. PLOS ONE 10, e0119499 (2015). 